\title{
Physiopathological and diagnostic aspects of cirrhotic cardiomyopathy
}

\section{Aspectos fisiopatológicos y diagnósticos de la miocardiopatía cirrótica}

\author{
Talia M. Leal-Alvarado1*, Ignacio Escalante-Sandoval², José L. Gálvez-Romero³, Paola Ávila-López ${ }^{4}$ \\ José L. Flores-Castillo ${ }^{4}$, and Montserrat Galván-Ramírez \\ ${ }^{1}$ Echocardiographic Cardiology; ${ }^{2}$ Gastroenterology; ${ }^{3}$ Research Head Office; ${ }^{4}$ Social Service in Research, Hospital Regional ISSSTE Puebla. Puebla, \\ Mexico
}

\begin{abstract}
Cirrhotic cardiomyopathy is characterized by the presence of structural and functional cardiac alterations in patients suffering from hepatic cirrhosis, without previously known cardiac causes that may explain it. Clinically, it is characterized by the presence of variable grades of diastolic and systolic dysfunction (SD), alterations in the electric conductance (elongation of corrected QT interval) and inadequate chronotropic response. This pathology has been related to substandard response in the management of patients with portal hypertension and poor outcome after transplant. Even when the first description of this pathology dates back from 1953, it remains a poorly studied and frequently underdiagnosed entity. Echocardiography prevails as a practical diagnostic tool for this pathology since simple measurements as the E/A index can show diastolic dysfunction. $S D$ discloses as a diminished ejection fraction of the left ventricle and the latent forms are detected by echocardiography studies with pharmacological stress. In recent years, new techniques such as the longitudinal strain have been studied and they seem promising for the detection of early alterations.
\end{abstract}

Key words: Cirrhotic cardiomyopathy. Hepatic cirrhosis. Systolic dysfunction. Diastolic dysfunction. Orthotopic liver transplant. Strain.

\section{Resumen}

La miocardiopatía cirrótica se caracteriza por la presencia de alteraciones cardiacas estructurales y funcionales en pacientes con cirrosis hepática, sin que existan otras causas de enfermedad cardiaca. Clínicamente se caracteriza por la presencia de grados variables de disfunción diastólica y sistólica, alteraciones de la conducción eléctrica (prolongación del intervalo QT) y respuesta cronotrópica inapropiada. Esta patología se ha relacionado con desenlaces clínicos adversos, mala respuesta en el manejo de la hipertensión portal y resultados desfavorables posterior a trasplante hepático ortotópico. A pesar de que las primeras descripciones datan de 1953, es una entidad poco estudiada y frecuentemente subdiagnosticada. El ecocardiograma es una herramienta de diagnóstico importante en esta entidad. Mediciones simples como el índice E/A pueden traducir disfunción diastólica. La disfunción sistólica se manifiesta con disminución de la fracción de eyección del ventrículo

\section{Correspondence:}

*Talia M. Leal-Alvarado

E-mail: talilealalv@g.mail.com
Date of reception: 24-03-2019

Date of acceptance: 15-08-2019

DOI: 10.24875/ACME.M20000110
Available online: 04-09-2020 Arch Cardiol Mex (Eng). 2020;90(2):154-162 www.archivoscardiologia.com 2604-7063 / @ 2019 Instituto Nacional de Cardiología Ignacio Chávez. Published by Permanyer. This is an open access article under the CC BY-NC-ND license (http://creativecommons.org/licenses/by-nc-nd/4.0/). 
izquierdo y las formas latentes se detectan mediante estudios de ecocardiografía con estrés farmacológico; en los últimos años se han estudiado otras técnicas como el strain longitudinal, que parecen prometedoras en la detección de alteraciones tempranas.

Palabras clave: Miocardiopatía cirrótica. Cirrosis hepática. Disfunción sistólica. Disfunción diastólica. Trasplante hepático ortotópico. Strain.

\section{Methods}

A search was carried out using keywords and free terms on different electronic platforms, including PubMed, Lilacs, and Cochrane. Results from previous 10 years were included in the search. Two-hundred and seven articles were obtained in PubMed and were discarded because of the titles. Eight results were obtained in Lilacs and two were discarded. In the database of the Cochrane library, five articles were collected out of 12 results. The MeSh keywords used in the search were: cirrosis hepática (hepatic cirrhosis), miocardiopatía (cardiomyopathy), miocardiopatía cirrótica (cirrhotic cardiomyopathy), diagnóstico (diagnosis), fisiopatología (pathophysiology), and tratamiento (treatment).

\section{Introduction}

Hepatic cirrhosis is chronic liver disease terminal stage. In our setting, the main causes of this condition are alcoholism and hepatitis $\mathrm{C}$. It is estimated that, by 2020, in Mexico, there will be 1.5 million people with hepatic cirrhosis, and 1.9 million by $2050^{1}$. In this pathological entity, circulatory dynamics is compromised and, therefore, multiple organs are affected; in this sense, a heart complication associated with hepatic cirrhosis called cirrhotic cardiomyopathy (CCM) has been conceptualized. The first study that described CCM without defining it as it is currently known was published in 1953 by Kowalsky and Abelmann ${ }^{2,3}$. Although initially it was particularly associated with alcoholic etiology, more recent studies suggest that diastolic dysfunction (DD) is also present in people with hepatic cirrhosis of non-alcoholic etiology ${ }^{4,5}$. The exact predisposing factors for some patients to develop CCM are unknown, as well as the time from hepatic cirrhosis diagnosis to the onset of this complication ${ }^{6,7}$. It has been estimated that CCM could be present in up to $50 \%$ of patients with hepatic cirrhosis; however, epidemiological data are sparse in Mexico due to lack of reporting and underdiagnosis ${ }^{8}$.

CCM is characterized by the presence of normal or increased cardiac output under basal conditions and incompetent under stress produced by pharmacological or pathological stimuli. The criteria that have been best accepted for its diagnosis are the presence of diastolic and/or systolic dysfunction (SD), accompanied by electrophysiological alterations such as QTc interval lengthening. To diagnose CCM, excluding any previous cardiac disease etiology is necessary ${ }^{9-12}$.

It is essential to consider CCM in the management of a patient with chronic liver disease due to his relationship with serious complications, such as hepatorenal syndrome (HRS), hepatopulmonary syndrome (HPS), and liver transplantation failure $\mathrm{e}^{11,13}$.

\section{Pathophysiological aspects}

\section{Hemodynamic changes}

The patient with cirrhosis has a redistribution of the circulating volume, and this anomalous distribution produces a state of "hyperdynamic circulation." In this condition, changes in liver architecture restrict blood flow to the right atrium and the volume is stored in the splanchnic circulation, which activates pathophysiological mechanisms that progressively induce vasodilation. These mechanisms have not been completely defined; however, an increase in vasodilator substances such as nitric oxide (NO), carbon monoxide (CO), adrenomedullin, tumor necrosis factor-alpha (TNF- $\alpha$ ), and endocannabinoids has been identified, with a simultaneous reduction of sensitivity to vasoconstrictor substances ${ }^{10,14-18 .}$

When these vasodilator substances are recognized by baroreceptors, compensatory systems such as the sympathetic nervous system, the renin-angiotensin-aldosterone system (RAAS), and antidiuretic hormone are activated, which contributes to the development of portal hypertension, defined by an increase in portal pressure gradient (difference between the pressures of the inferior vena cava and the portal vein), which is considered clinically significant when it is equal to or higher than $10 \mathrm{mmHg}^{9,19}$. The importance of understanding the pathophysiological mechanisms lies in the prevention of the appearance and optimal management 


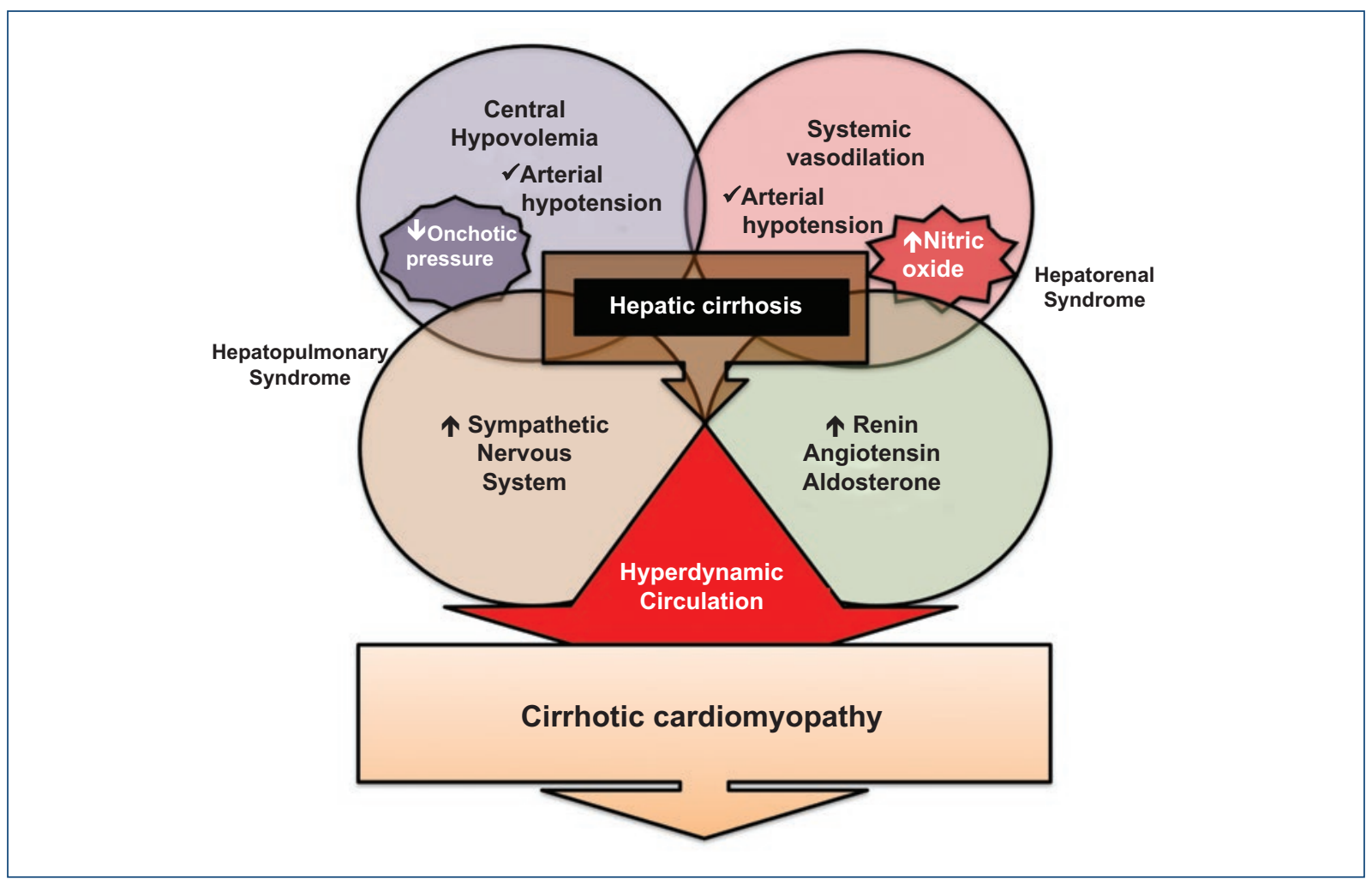

Figure 1. Pathophysiology of cirrhotic cardiomyopathy. The cirrhotic patient exhibits a redistribution of the circulating volume, which is a state known as "hyperdynamic circulation." It is characterized by systemic vasodilation, central hypovolemia, and sympathetic nervous system, and renin-angiotensin-aldosterone system activation. Released cytokines and molecules are associated with damage to the myocardiocyte and vascular disorders that contribute to the development of refractory ascites, hepatorenal syndrome, and hepatopulmonary syndrome (adapted from Altayar et al., $2019^{11}$ and Chayanupatkul et al., 2014'3).

of complications such as ascites, HRS, HPS, and CCM (Fig. 1) ${ }^{9}$.

\section{Molecular changes}

In CCM, cardiomyocytes undergo changes that alter the functions of protein $\mathrm{G}$-coupled receptors ( $\beta$-adrenergic, muscarinic, and endocannabinoid). As a consequence, there is a decreased response to stress associated with electrical changes and contractility compromise ${ }^{20,21}$.

Activation of the sympathetic nervous system increases inotropism and chronotropism; however, this constant stimulation is excessive and induces myocardial protection measures; first, through $\beta 1$ and $\beta 2$ receptors internalization to reduce the excitatory response, followed by an increase in $\beta 3$ receptor expressions (inhibitory effect). In the end, these protective measures induce an insufficient response to stress ${ }^{2,22}$.
Intravascular volume relative reduction activates RAAS and antidiuretic hormone, thus increasing water and sodium retention, with hyperdynamic circulation further deterioration ${ }^{20}$. In addition, on RAAS activation, angiotensin II takes an alternate route to become angiotensin 1-7, which generates a vasodilator effect when coupled to the MAS receptor. Blockage of this receptor constitutes a therapeutic target ${ }^{2}$.

\section{Cell changes}

Patients with CCM are in an advanced stage of liver disease. In them, it is common for bacterial translocation to be produced, which activates the immune system through lipopolysaccharides and bacterial genetic material; in response, mediators such as interleukin-1, TNF- $\alpha$, endocannabinoids, oxygen and nitrogen reactive species are expressed, which modify the cardiomyocyte physiological responses ${ }^{6,23}$. In experimental models, these mediators have been found to induce a reduction 


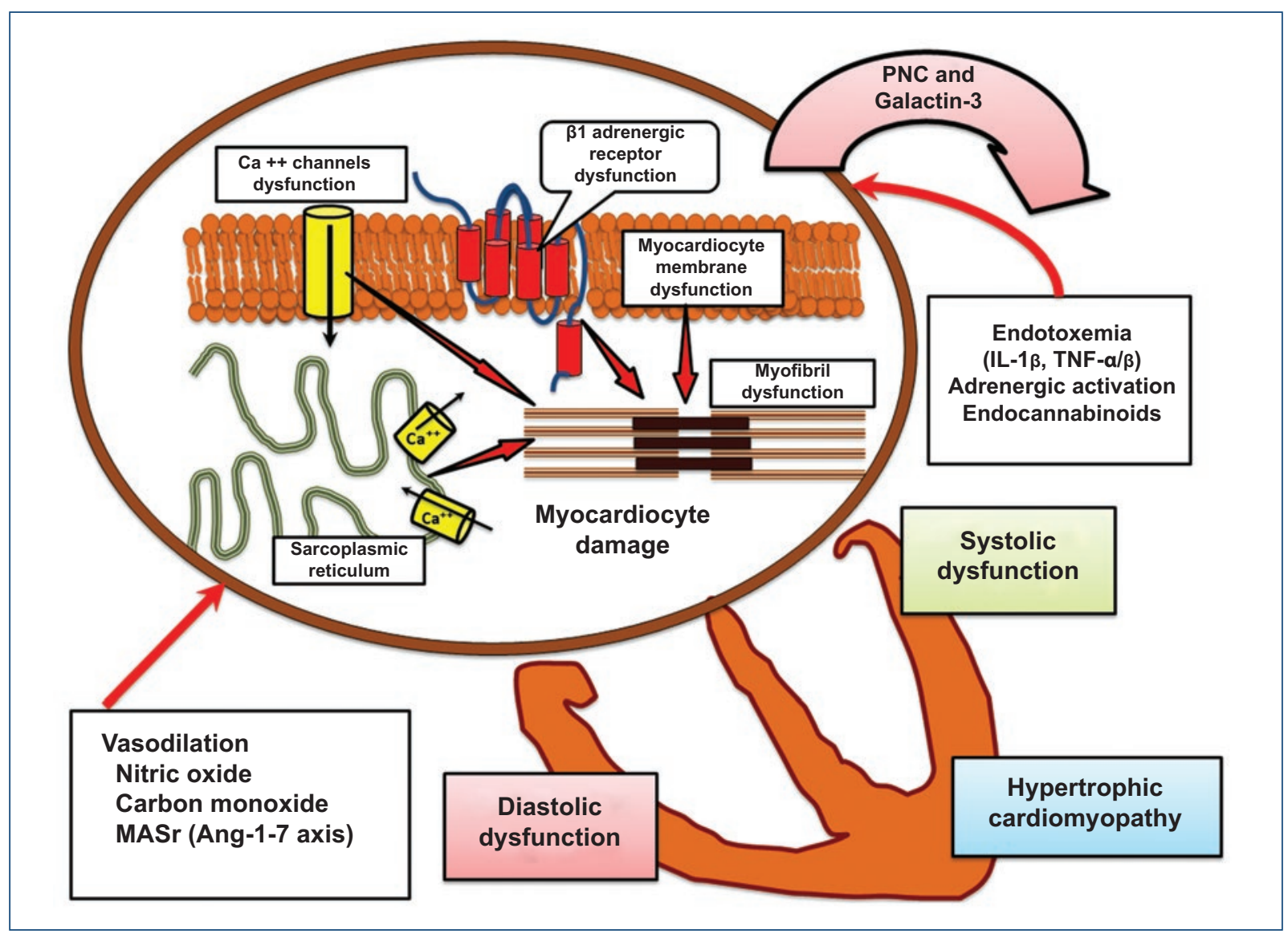

Figure 2. Liver cirrhosis-associated cardiomyocyte dysfunction. Dysfunction is due to changes in the receptors ( $\beta$-adrenergic and calcium) that modulate myocardial contractile response. Changes are indirectly produced by vasodilation (nitric oxide, carbon monoxide, and angiotensin 1-7 axis) and directly in the cardiomyocyte due to factors that alter receptor expression (bacterial translocation endotoxemia, immune activation with IL-1 and TNF, reactive oxygen species, and endocannabinoids), and together modify cardiomyocyte physiological responses (adapted from Páll et al., 201410; Møller et al., 2006'5; Gitman et al., 201817, and Licata et al., 201418).

IL-1: interleukin 1; MASr: angiotensin 1-7 axis MAS receptor; TNF- $\alpha / \beta$ : tumor necrosis factor $\alpha / \beta$.

of cAMP in the cardiomyocyte, thus altering intracellular signaling and intracellular calcium flow. These modifications induce a reduced contractile response and increase passive tension. CAMP decrease produces a decline in protein kinase $A$, which phosphorylates L-type calcium receptors and ryanodine receptors, which generates higher intracellular calcium release, thus altering myofibril contraction and inducing extrinsic apoptosis ${ }^{23}$. In turn, elasticity is compromised due to an increase in type 1 collagen, a decrease in type 3 collagen and titin phosphorylation reduction $20,23,24$.

TNF- $\alpha$ stimulates NO formation and activates cGMP second messenger; thus, through a phosphodiesterase, it also reduces cAMP concentration². On the other hand, endocannabinoids, by stimulating cannabinoid type 1 receptor, also reduce cAMP concentration (due to the fact of being linked to Gi protein). Interleukins, together with reactive oxygen and nitrogen species, have been observed to alter the lipid membrane, specifically cholesterol lecithin acetyltransferase, which influences on cholesterol/phospholipid relationship by directly altering $\mathrm{K}^{+}$and $\mathrm{Ca}^{++}$receptors expression, with this being related to the characteristic electrical disturbances of QT prolongation (Fig. 2) 20,23.

Aldosterone elevation increases the production of metalloproteinases and fibroblast growth factor- $\beta$, further contributing to myofibrils dysfunction. On the other hand, in liver cirrhosis, there is an increase in lipophilic bile acids such as cholic acid, which reduces contractility and alters $\beta$-adrenergic receptor; therefore, it is likely that ursodeoxycholic acid may reduce this effect ${ }^{20}$. 


\section{Cardiac function alteration}

\section{$D D$}

DD refers to a decrease in left ventricular distensibility and relaxation, produced by an increase in wall stiffness secondary to myocardial hypertrophy, fibrosis, and sub-endothelial edema, with a progressive increase in filling pressures ${ }^{15,25,26}$. Most studies propose $\mathrm{DD}$ as a main finding on echocardiogram and as a predecessor of systolic alterations $\mathbf{s}^{19,20,27-29}$.

Altered diastolic function usually occurs in situations such as exercise, infectious processes, certain medications, or after procedures such as transjugular intrahepatic portosystemic shunt (TIPS) placement, or with reperfusion after orthotopic liver transplantation $(\mathrm{OLT})^{15,30}$. TIPS and OLT return a significant amount of splanchnic circulation-sequestered volume to the central circulation and, consequently, increase filling pressures and myocardial stress, which worsens the hemodynamic function and caused heart failure in some patients ${ }^{27,31,32}$.

Patients without ascites can have cardiac dysfunction compensated due to increased preload; conversely, in patients with ascites, afterload is reduced due to systemic arterial vasodilation. DD severity before transplantation is related to increased mortality, as well as to a higher degree of tricuspid and mitral regurgitation, which is considered to be a prognostic factor in post-transplanted patients ${ }^{14,28,33-35}$.

\section{$S D$}

SD has been established as one of CCM diagnostic criteria. However, this dysfunction is usually found in a latent state due to systolic function protective mechanisms, such as decreased afterload and vascular resistance ${ }^{13,19}$. Preserved cardiac output is compromised in stressful situations, and it is then when patients experience SD; a clear example of this mechanism is the overt appearance of systolic failure after TIPS insertion or in post-transplanted patients ${ }^{10}$. Usually, the technique used for systolic function echocardiographic evaluation is left ventricular ejection fraction (LVEF) determination with Simpson's modified method ${ }^{20}$.

\section{Electrocardiographic changes}

QTc interval is the most common electrocardiographic alteration in patients with $\mathrm{CCM}$, which is observed in $40-50 \%$. Usually, the Bazett formula is used to correct the QT interval; however, in individuals with liver cirrhosis, the formula where a QTc interval higher than 450 $\mathrm{ms}$ in men and $470 \mathrm{~ms}$ in women is regarded as pathological is recommended $20,23,36-38$.

This lengthening is attributed to alterations in the potassium channels and alteration in the flow of this ion during action potential phases 2 and $3^{39}$. In turn, there is a concentration reduction in the potassium channels of the plasma membrane; this alteration induces a paradoxical response in which adrenergic stimulation prolongs repolarization and slows down the heart muscle; this reaction explains the occurrence of SD during physical activity ${ }^{7,36}$.

The prevalence of QTc prolongation has been associated the with the Child-Pugh scale, up to $60 \%$ at stage $C^{9,36,39}$. On the other hand, QTC interval relationship with cardiovascular events is controversial; during OLT, discrepancies have been found between the perioperative results of patients with CCM. Various authors refer that there is an increase in mortality and in the occurrence of ventricular arrhythmias; in contrast, other studies belittle this relationship ${ }^{40-44}$. OLT has been shown normalize QTc interval length in more than $80 \%$ of patients 6 months after surgery ${ }^{25}$.

\section{Complications}

\section{HRS and HPS}

HRS is defined as the presence of liver disease and reduced glomerular filtration secondary to LVEF alterations. It is a manifestation of circulatory dysfunction and, therefore, mean arterial pressure and cardiac output are independent predictors of the development of HRS $^{16,45-47}$. Once established, HRS accelerates cardiac output deterioration, with lower preload and sympathetic nervous system impaired response. Since albumin can help prevent HRS, by volumetric expansion and increased preload, management is currently carried out with albumin and terlipressin ${ }^{45,48}$.

HPS is defined as the presence of liver disease and pulmonary vascular dilation, which is observed, from a practical point of view, as an abnormal alveolar-arterial oxygen gradient (corrected for age) $>15 \mathrm{mmHg}^{16,49}$.

The absence of symptoms during compensated liver cirrhosis delays HPS diagnosis, although it should be suspected in the presence of nonspecific signs such as tachypnea, polypnea, clubbing of the fingers or toes, and cyanosis ${ }^{50}$. HPS is considered one of the phases of multiple organ failure, which characterizes liver failure ${ }^{28,51}$. 


\section{Diagnostic methods}

\section{Montreal criteria}

In 2005, the World Congress of Gastroenterology was held in Montreal, where specific criteria for the diagnosis of CCM were formulated, as well as a structured description, where it was defined as inefficient contractile function in the presence of stress and/or altered diastolic relaxation with electrophysiological abnormalities in the absence of another known cardiac cause. Diagnostic criteria are based on the finding of diastolic and SD by conventional echocardiography plus supporting criteria, including structural and electrophysiological changes and peptide elevation (Table 1) $)^{4,19}$.

\section{Echocardiographic findings}

\section{TWO-DIMENSIONAL (2D) ECHOCARDIOGRAPHY}

In patients with CCM, different series coincide in that the most common echocardiographic finding is a reduction of the E/A ratio. A value $<1$ is an accepted indicator of $\mathrm{DD}$, which in turn is linked to adverse events such as decreased ascites clearance and higher mortality after TIPS placement ${ }^{27,52}$. E/A ratio may be insufficient for DD evaluation, since sometimes its value can be normal or higher despite the severity of dysfunction, and thus it should not be taken as a sole or absolute CCM indicator ${ }^{28}$.

\section{TISSUE DopPLER IMAGING}

Tissue Doppler imaging application with mitral annulus E-wave measurement has also been suggested to be superior to $2 \mathrm{D}$ echocardiography for assessing $\mathrm{DD}$ due to its independence from loading conditions, with only tissue dynamics being measured $20,28,53,54$.

\section{SPECKLE TRACKING}

Speckle tracking is an echocardiographic technique that allows left ventricular stress or deformation (strain) overall assessment in three directions, by tracking acoustic marks within the cardiac cycle ${ }^{28,55}$. In recent years, this technique has acquired more importance because it is a non-invasive method that is useful for measuring the systolic function at rest ${ }^{3,7,28,56}$. Measurement of stress or deformation with this modality has a low margin of measurement error ${ }^{57}$.
Table 1. Cirrhotic cardiomyopathy diagnostic criteria, Canada 2005 (absence of known heart disease)

\begin{tabular}{|c|c|c|}
\hline $\begin{array}{l}\text { Systolic } \\
\text { dysfunction }\end{array}$ & $\begin{array}{l}\text { Diastolic } \\
\text { dysfunction }\end{array}$ & Supporting criteria \\
\hline $\begin{array}{l}\text { - LVEF at rest } \\
<55 \% \\
\text { - Decreased } \\
\text { contractility } \\
\text { under } \\
\text { physiological or } \\
\text { pharmacological } \\
\text { stress }\end{array}$ & $\begin{array}{l}- \text { E/A ratio }<1.0 \\
- \text { DT }>200 \mathrm{~ms} \\
- \text { LVIRT }>80 \mathrm{~ms}\end{array}$ & $\begin{array}{l}\text { - Chronotropic } \\
\text { incompetence } \\
\text { - Electromechanical } \\
\text { desynchronization } \\
\text { - Structural changes: left } \\
\text { atrium enlargement and } \\
\text { left ventricular } \\
\text { hypertrophy } \\
\text { - Peptide elevation: } \\
\text { troponin I, BNP, } \\
\text { pro-BNP }\end{array}$ \\
\hline
\end{tabular}

LVEF: left ventricular ejection fraction; E/A: rapid protodiastolic filling and left atrial contraction ratio; DT: deceleration time; LVIRT: left ventricular isovolumetric relaxation time; BNP: brain natriuretic peptide. Adapted from Wiese et al., $2014^{19}$.
Hamami et al. studied the systolic function in patients with CCM resorting to different echocardiographic techniques, and identified a prevalence of $17.5 \%$ using LVEF; however, using tissue Doppler to measure left ventricular lateral wall s-wave $(<8 \mathrm{~cm})$, they identified a prevalence of $43.1 \%$, while with the measurement of strain or deformation, the observed prevalence was $40 \%{ }^{58}$. On the other hand, they observed a significantly lower frequency of basal than apical strain or deformation ${ }^{58}$.

\section{Stress test}

Given that systolic ventricular dysfunction in CCM is usually in a latent state, it can be unmasked by physical or pharmacological stress; in the latter scenario, tests with dobutamine are used, where there is a marked decrease of cardiac output under effort conditions in comparison with healthy subjects ${ }^{28,59,60}$.

\section{Magnetic resonance imaging (MRI)}

There are other imaging methods that have been used to detect cardiac structural alterations, among which MRI has been positioned as the gold standard in the diagnosis of myocardial functional and morphological disorders, and it is therefore useful in the detection of subclinical changes that are previous to dysfunction in patients with CCM. Its availability and cost are major disadvantages as a method of choice in the assessment of stress or deformation in the cirrhotic patient ${ }^{8,28}$. 


\section{Brain natriuretic peptide (BNP) and atrial natriuretic peptide}

BNP is a 32-amino acid polypeptide secreted by the ventricles. Its elevation is related to ventricular overload; it acts as a RAAS compensatory hormone by removing sodium and water ${ }^{6}$. DD is indirectly related to cardiac markers such as atrial natriuretic peptide and BNP which are signs of stress and volume overload within the heart ${ }^{61,62}$. As ventricular hypertrophy increases, BNP serum levels rise. At CCM initial stage, this marker can start raising and thus it can act as an early indicator for the diagnosis of this complication?.

\section{Other laboratory tests}

Troponin I has been linked to a decrease of the left ventricular mass and decreased systolic volume. Postliver transplantation patients with a troponin I value higher than $0.07 \mathrm{ng} / \mathrm{mL}$ have been reported be at higher risk of mortality or rejection of the transplanted liver; however, their values have not been associated with the severity of liver cirrhosis, and its usefulness is therefore limited in the post-liver transplantation follow-up ${ }^{6,61}$. Assessing endocannabinoid concentrations have also been possible, which are considered to be altered with values higher than $5 \mathrm{ng} / \mathrm{mL}$, with this elevation predicting rapid decompensation in the cirrhotic patient ${ }^{63}$.

Galactin-3 has shown an association with myocardial fibrosis, and it is increased in liver cirrhosis with impaired cardiac function. Furthermore, in a comparative study, it was more sensitive than BNP; however, BNP was more specific for myocardial damage ${ }^{21,64}$.

\section{Treatment}

\section{Pharmacological management}

Current pharmacological management has not been shown to improve CCM evolution; however, various alternatives have been assessed for the control of complications associated with liver cirrhosis hyperdynamic state and its interaction with myocardial function ${ }^{20,28}$. Among these drugs, diuretics have been shown to be useful in patients with congestive heart failure, however; this situation is not usual in CCM, since existing arterial vasodilation reduces afterload.

Aldosterone antagonists reduce hepatic venous gradient and myocardial wall thickness, but they do not revert $D^{22}$. Nonselective beta-blockers are helpful for preventing bleeding from esophageal varices and have shown greater benefits with carvedilol due to its antioxidant and antifibrotic effects, although given the lack of randomized clinical trials, they should not be used to prevent portal hypertension complications ${ }^{65-68}$.

As a forward-looking perspective, there are targeted therapeutic strategies, such as the use of CB1 receptor antagonists, NO synthase blockers, transforming-growth factor- $\beta$ blockers and angiotensin 1-7 activity blockade; in addition, ursodeoxycholic acid can probably reduce the cardiotoxic effect produced by lipophilic bile acids ${ }^{2,13,20}$.

\section{Liver transplantation}

The only treatment that reverts CCM is OLT but, unfortunately, establishing a method to identify patients susceptible of improvement has not been possible. When a favorable response is obtained after liver transplantation, peripheral vascular resistance increases and portal pressure, diastolic function, wall thickness, and response to exercise are normalized, including a reversal in electrocardiographic alterations. In the immediate post-operative period, CCM transiently worsens for days or weeks, with the referred improvement being observed in 6-12 months ${ }^{69}$. On the other hand, in some patients, increased cardiac output persists for 2 years after transplantation ${ }^{39,70}$.

During transplantation, adequate perfusion should be maintained to prevent acute heart failure, since changes in peripheral vascular resistance are produced and therefore there is an increase in venous return, which makes it difficult to maintain an adequate output, with cardiac function deterioration and development of pulmonary edema.

Patients with QTc prolongation in addition to BNP and troponin I positive levels should be considered as having a higher risk of acute heart failure during transplantation and require transesophageal echocardiogram during surgery for monitoring ${ }^{71}$.

In the post-operative period, the preload increase that follows reperfusion may predispose to arrhythmias, myocardial infarctions, post-perfusion syndrome, heart failure, and sudden death; therefore, continuous monitoring of the heart function is recommended ${ }^{11,31,69}$.

\section{Conclusions}

Patients with liver cirrhosis experience a hemodynamic imbalance, which in the long-term compromises the function of multiple organs. CCM is the cardiac 
expression resulting from this pathological state. Incompetent cardiac output, diastolic, and SD, QTc interval prolongation and other $\mathrm{CCM}$ characteristics contribute to a higher hemodynamic decompensation that is associated with serious complications such as the onset of HRS, HPS, and refractory ascites.

The Montreal criteria, which remain in force in most of the literature, do not consider the new echocardiographic techniques for CCM diagnosis. It is important bearing in mind that these techniques have demonstrated their usefulness in the diagnosis of pathologies that compromise the myocardium, and allow the detection of subclinical abnormalities that can guide CCM timely diagnosis, thus avoiding invasive procedures such as drug administration. Markers such as BNP, troponin I, and galactin-3 have also been shown to be useful for CCM diagnosis.

So far, there is no consensus on CCM therapeutic approach. OLT appears to be the only effective solution; however, if cardiac dysfunction is highly compromised, it can cause post-transplantation failure. CCM timely diagnosis should be part of the usual work-up of patients with decompensated liver cirrhosis, using available resources in each setting, bearing in mind that early approach might have an effect on morbidity and mortality.

\section{Funding}

The present investigation has not received specific aid from public or commercial sector agencies or non-profit entities.

\section{Conflicts of interest}

The authors refer that they have no conflicts of interest.

\section{Ethical disclosures}

Protection of people and animals. The authors declare that no experiments were performed on humans or animals for this investigation.

Confidentiality of data. The authors declare that no patient data appear in this article.

Right to privacy and informed consent. The authors declare that no patient data appear in this article.

\section{References}

1. Instituto Mexicano del Seguro Social, Dirección de prestaciones médicas, Unidad de atención médica, Coordinación de unidades médicas de alta especialidad, División de excelencia clínica. Guía de Referencia Rápida Diagnóstico y Tratamiento de la Insuficiencia Hepática Crónica. México: Instituto Mexicano del Seguro Social; 2009.
2. Fede G, Privitera G, Tomaselli T, Spadaro L, Purrello F. Cardiovascular dysfunction in patients with liver cirrhosis. Ann Gastroenterol. 2015; 28(1):31-40.

3. Kowalski HJ, A W. The cardiac output at rest in Laennec's cirrhosis. J Clin Invest. 1953;32:1025-1033.

4. Raevens S, De Pauw M, Geerts A, Berrevoet F, Rogiers X, Troisi RI, et al. Prevalence and outcome of diastolic dysfunction in liver transplantation recipients. Acta Cardiol. 2014:69(3):273-80.

5. Somani P, Chaurasia A, Rathi P. Diastolic dysfunction characterizes cirrhotic cardiomyopathy. Indian Heart J. 2014;66:649-55.

6. Mocarzel LOC, Rossi MM, Miliosse BM, Lanzieri PG, Gismondi RA.Cirrhotic Cardiomyopathy: A New Clinical Phenotype. Arq Bras Cardiol. 2017;108(6):564-8.

7. Bicca J, Porto L, Oliveira T, Gismondi R, Mocarzel L, Gemal P. Cardiomiopatía cirrótica. International J Cardiovascular Science. 2016;29(2):139-48.

8. Carvalho MVH, Kroll PC, Kroll RTM, Carvalho VN. Cirrhotic cardiomyopathy: the liver affects the heart. Brazilian J Med Biol Res. 2019;52:1-9.

9. Møller S, Bernardi M. Interactions of the heart and the liver. Eur Heart J 2013;34:2804-11.

10. Páll A, Czifra A, Vitális Z, Papp M, Paragh G, Szabó Z. Pathophysiological and clinical approach to cirrhotic cardiomyopathy. J Gastrointestin Liver Dis. 2014;23:301-10.

11. Altayar O, Lisker-melman M. Physiologic adaptation or cirrhotic cardiomyopathy: It is time for new definitions. J Card Fail. 2019;25(3):173-5.

12. Rand EB. Cirrhotic cardiomyopathy in children with bibliary atresia: A new objective parameter to predict morbidity and mortality on the waitlist - and beyond! Hepatology. 2019;69(3):940-2.

13. Chayanupatkul M, Liangpunsakul S. Cirrhotic cardiomyopathy: Review of pathophysiology and treatment. Hepatol Int. 2014;8:308-15.

14. Falletta C, Fili D, Nugara C, Di Gesaro G, Minà C, Baravoglia CM, et al. Diastolic dysfunction diagnosed by tissue Doppler imaging in cirrhotic patients : Prevalence and its possible relationship with clinical outcome. Eur J Intern Med. 2015;26(10):830-4

15. Møller S, Henriksen J. Cardiopulmonary complications in chronic liver disease. World J Gastroenterol. 2006:12(4):526-38.

16. Møller S, Bendtsen F. Complications of cirrhosis. A 50 years flashback. Scandinavian J Gastroenterology. 2015;:1-18.

17. Gitman M, Albertz M, Nicolau-Raducu R, Aniskevich S, Pai S. Cardiac diseases among liver transplant candidates. Clin Transplant. 2018:32.

18. Licata A, Mazzola A, Ingrassia D, Calvaruso V, Cammà C, Craxì A. Clinical implications of the hyperdynamic syndrome in cirrhosis. Eur $\mathrm{J}$ Intern Med. 2014:25:795-802.

19. Wiese S, Hove J, Bendtsen F, Møller S. Cirrhotic cardiomyopathy: Pathogenesis and clinical relevance. Nat Rev Gastroenterol Hepatol. 2014:11:177-86.

20. Karagiannakis D, Papatheodoridis G, Vlachogiannakos J. Recent advances in cirrhotic cardiomyopathy. Dig Dis Sci. 2015;60(5):1141-51.

21. Abbas W, et al. Galactin-3 and brain natriuretic peptide versus conventional echocardiography in the early detection of cirrhotic cardiomyopathy. 2016;2016:367-74

22. D'Albuquerque $L$, et al. $\beta$-Blocker therapy for cirrhotic cardiomyopathy. Eur J Gastroenterol Hepatol. 2018;30:930-7.

23. Ruiz-del-árbol L, Serradilla R. Hemodynamic advances in cirrhosis cirrhotic cardiomyopathy. 2015;21:11502-21.

24. Marcheta JD. La cardiomyopathie du cirrhotique: un bref aperçu. 2015:86-91.

25. Izzy M, Jae $\mathrm{OH}$, Watt K. Cirrhotic cardiomyopathy after transplantation: neither the transient nor innocent bystander. Hepatology. 2017;777:1-36.

26. Kwon $\mathrm{H}$, Hwang $\mathrm{G}$. Cardiovascular dysfunction and liver transplantation. 2018.

27. González M, Albillos M. Disfunción cardiaca en la cirrosis. Gastroenterol y Hepatol. 2005;28:47-51.

28. Rahman S, Mallett S. Cirrhotic cardiomyopathy: Implications for the perioperative management of liver transplant patients. 2015;7:507-20.

29. Rodríguez-Gandía M, et al. Diastolic dysfunction is a predictor of poor outcomes in patients with cirrhosis, portal hypertension, and a normal creatinine. Hepatology. 2013:58:1732-41.

30. Lee $Y$, Lee J. Cirrhotic cardiomyopathy: An independent prognostic factor for cirrhotic patients. 2018:372-373.

31. Zardi E, et al. Cirrhotic cardiomyopathy in the pre- and post-liver transplantation phase. J Cardiol. 2016:67:125-30

32. Castedal M, Olausson M. Impact of peri-transplant heart failure \& left-ventricular diastolic dysfunction on outcomes following liver transplantation. 2012;1-8.

33. Merli M, et al. Survival at 2 years among liver cirrhotic patients is influenced by left atrial volume and left ventricular mass. Liver Int. 2017;37.

34. Kazankov K, et al. Resting myocardial dysfunction in cirrhosis quantified by tissue Doppler imaging. 2011;534-40.

35. Papastergiou V, et al. Ultrasonographic prevalence and factors predicting left ventricular diastolic dysfunction in patients with liver cirrhosis: Is there a correlation between the grade of diastolic dysfunction and the grade of liver disease? 2012:6-11.

36. Trevisani $F$, et al. QT interval prolongation by acute gastrointestinal bleeding in patients with cirrhosis. 2012:1-6 
37. Maggioli C, Zaccherini G. QT interval prolongation in liver cirrhosis : innocent bystander or serious threat? 2012:57-66.

38. Główczyńska R, Raszeja-Wyszomirska J. Pretransplant QT interval : The relationship with severity and etiology of liver disease and prognostic value after liver transplantation. 2018:622-30.

39. Gassanov N, et al. Cirrhotic cardiomyopathy: A cardiologist' s perspective. $2014 ; 20: 15492-8$

40. Jaber W, Cywinski J. Impact and persistence cirrhotic cardiomyopathy after liver transplantation. 2016.

41. Zurick A, et al. Alterations in corrected QT interval following liver transplant in patients with end-stage liver disease. Clin Cardiol. 2010:33:672-7.

42. Bal JS, T P. Prolongation of QTc interval: relationship with etiology and severity of liver disease, mortality and liver transplantation. Liver Int. 2003;23:243-8.

43. Patel $D$, et al. QT interval prolongation in end-stage liver disease cannot be explained by nonhepatic factors. Ann Noninvasive Electrocardiol. 2014:574-581.

44. Flaherty $\mathrm{D}$, et al. Preoperative QTc interval is not associated with in traoperative cardiac events or mortality in liver transplantation patients. J. Cardiothorac Vasc Anesth. 2018;000:1-6.

45. Acevedo J, et al. Hepatorenal syndrome: Update on diagnosis and therapy. 2017;9:293-9.

46. Solà G, Wong F, Mitra K, K N. Hepatorenal syndrome. Nat Rev. 2018.

47. Mocarzel L, Lima D, Dias D, Lanzieri P, C P. Hepatorenal syndrome with cirrhotic cardiomyopathy: A case series of a new approach for re-fractory patients. J Gastroenterol Hepatol Res. 2017;6.

48. Zardi E, et al. Cirrhotic cardiomyopathy. J Am Coll Cardiol. 2010;56(7):539-49

49. Møller S, Bendtsen F. Cirrhotic multiorgan syndrome. Dig Dis Sci. 2015;60:3209-25

50. The European Association for the Study of the Liver. EASL Clinica Practice Guidelines for the management of patients with decompensated cirrhosis. J Hepatol. 2018.

51. BernalW, etal. Acute-on-chronic liverfailure. Lancet. Año;386(10003):1576-87.

52. Rabie $R$, Cazzaniga M, Salerno F, Wong $F$. The use of E/A ratio as a predictor of outcome in cirrhotic patients treated with transjugular intrahepatic portosystemic shunt. Am J Gastroenterol. 2009;104:2458-66.

53. Rimbaş $R$, et al. New definition criteria of myocardial dysfunction in patients with liver cirrhosis: A speckle tracking and tissue Doppler imaging study. Ultrasound Med Biol. 2018:44:562-74.

54. Wong F, et al. The cardiac response to exercise in cirrhosis. 2001

55. Collier P, Phelan D, K A. A test in context: Myocardial strain measured by speckle-tracking echocardiography. J Am Coll Cardiol. 2017;69(8):1043-56.
56. Carvalheiro $F$, et al. Diastolic dysfunction in liver cirrhosis : Prognostic predictor in liver. Transplant Proc. 2016;48:128-31.

57. $\mathrm{Ng} \mathrm{A}$, et al. Incremental value of 2-dimensional speckle tracking strain maging to wall motion analysis for detection of coronary artery disease in patients undergoing dobutamine stress echocardiography. Am Hear J. 2009;158(5):836-44.

58. Hammami $\mathrm{R}$, et al. Cirrhotic cardiomyopathy: is there any correlation between the stage of cardiac impairment and the severity of liver disease ? Libyan J Med. 2017;12:

59. Wiese S, Hove J, Møller S. Cardiac imaging in patients with chronic liver disease. 2015:1-10

60. Kim M, et al. Dobutamine stress echocardiography for evaluating cirrhotic cardiomyopathy in liver cirrhosis. 2010:376-82.

61. T T, Qi X. Pro-brain natriuretic peptide and troponin T-hypersensitivity levels correlate with the severity of liver dysfunction in liver cirrhosis Jiancheng. Am J Med Sci. 2017.

62. Naqvi, et al. The heart matters when the liver shatters! Cirrhotic cardiomyopathy: frequency, comparison, and correlation with severity of disease. 2016;11.

63. Voiosu A, et al. The diagnostic and prognostic value of serum endocan in patients with cirrhotic cardiomyopathy. 2018:182-192.

64. Yilmaz V, et al. Relationship of increased serum brain natriuretic peptide levels with hepatic failure, portal hypertension and treatment in patients with cirrhosis. Turkish J. Gastroenterol. 2010;21.

65. Karagiannakis D, Vlachogiannakos J. Diastolic cardiac dysfunction is a predictor of dismal prognosis in patients with liver cirrhosis. 2014.

66. Cox L, Li J, Nelson H, Lockey R. Allergen immunotherapy: A practice parameter second update. J Allergy Clin Immunol. 2007;120:S1-55.

67. D'Albuquerque $F$, et al. $\beta$-Blocker therapy for cirrhotic cardiomyopathy: a randomized-controlled trial. Eur J Gastroenterol Hepatol. 2018;30:930-7.

68. Silvestre M, Farias A, Ramos D, Furtado M, Rodrigues A, Ximenes R et al. $\beta$-Blocker therapy for cirrhotic cardiomyopathy: a randomized-controlled trial. Eur J Gastroenterol Hepatol. 2018;30(8):930-37

69. Liu H, L S. What happens to cirrhotic cardiomyopathy after liver transplantation? Hepatology. 2005:42:1205.

70. Sonny A, Govindarajan S, Jaber W, Cywinski J. Systolic heart failure after liver transplantation: Incidence, predictors, and outcome. 2018:1-9.

71. Farr M, Schulze P. Recent advances in the diagnosis and managemet of cirrhosis-associated cardiomyopathy in liver transplant candidates: Advanced echo imaging, cardiac biomarkers, and advanced heart failure therapies. Clin Med Insights Cardiol. 2015;8(Suppl 1):67-74. 